\title{
Society of Hospital Medicine Position on the American Board of Pediatrics Response to the Pediatric Hospital Medicine Petition
}

\author{
Weijen W Chang, MD*, Akshata M Hopkins, MD², Kris P Rehm, MD³, Sandra L Gage, MD, PhD", Mark Shen, MD MBA ${ }^{5}$
}

'Division of Pediatric Hospital Medicine, Baystate Children's Hospital, Springfield, Massachusetts; ${ }^{2}$ Division of Pediatric Hospital Medicine, Johns Hopkins All Children's Hospital, St. Petersburg, Florida; ${ }^{3}$ Division of Pediatric Hospital Medicine, Monroe Carell Jr. Children's Hospital at Vanderbilt, Nashville, Tennessee; ${ }^{4}$ Department of Pediatric Hospital Medicine, Phoenix Children's Hospital, Phoenix, Arizona; ${ }^{5}$ Dell Medical School, University of Texas, Austin, Texas.

\section{.} he first Pediatric Hospital Medicine (PHM) fellowships in the United States were established in 2003; and since then, the field has expanded and matured dramatically. This growth, accompanied by greater definition of the role and recommended competencies of pediatric hospitalists, ${ }^{2}$ culminated in the submission of a petition to the American Board of Pediatrics (ABP) in August 2014 to consider recognition of $\mathrm{PHM}$ as a new pediatric subspecialty. ${ }^{3}$ After an 18-month iterative process requiring extensive input from the Joint Council of Pediatric Hospital Medicine, ABP subcommittees, the Association of Medical School Pediatric Department Chairs, the Association of Pediatric Program Directors, and other prominent pediatric professional societies, the ABP voted in December 2015 to recommend that the American Board of Medical Subspecialties (ABMS) recognize PHM as a new subspecialty. ${ }^{3}$

The ABP subsequently announced three pathways for board certification in PHM:

- Training pathway for those completing an Accreditation Council for Graduate Medical Education-accredited twoyear PHM fellowship program;

- Practice pathway for those satisfying ABP criteria for clinical activity in PHM for four years prior to exam dates (in 2019, 2021, and 2023), initially described as "direct patient care of hospitalized children $\geq 25 \%$ full-time equivalent (FTE) defined as $\geq 450-500$ hours per year every year for the preceding four years";

- Combined pathway for those completing less than two years of fellowship, who would be required to complete two years of practice experience that satisfy the same criteria as each year of the practice pathway. ${ }^{5}$

While the training pathway met near-uniform acceptance, concerns were raised through the American Academy of Pediatrics Section of Hospital Medicine (AAP SOHM) Listserv regarding the practice pathway, and by extension, the combined pathway. Specifically, language describing the necessary characteristics of acceptable PHM practice was felt to be vague and not transparent. Listserv posts also raised concerns regarding the potentia

*Corresponding Author: Weijen W. Chang, MD SFHM FAAP; E-mail: weijen. chang.md@bhs.org; Telephone: (413) 794-2398; Twitter: @wwchang

Published online first September 16, 2019.

Received: September 11, 2019; Accepted: September 12, 2019

(C) 2019 Society of Hospital Medicine DOI 10.12788/jhm.3326 exclusion of "niche" practices such as subspecialty hospitalists and newborn hospitalists. As applicants in the practice pathway began to receive denials, opinions voiced in listserv posts were increasingly critical of the ABP's lack of transparency regarding the specific criteria adjudicating applications.

\section{ORIGIN OF THE PHM PETITION}

A group of hospitalists, led by Dr. David Skey, a pediatric hospitalist at Arnold Palmer Children's Hospital in Orlando, Florida, created a petition which was submitted to the ABP on August 6, 2019, and raised the following issues:

- "A perception of unfairness/bias in the practice pathway criteria and the way these criteria have been applied.

- Denials based on gaps in employment without reasonable consideration of mitigating factors.

- Lack of transparency, accountability, and responsiveness from the ABP." 6

The petition, posted on the AAP SOHM listserv and signed by 1,479 individuals, 7 raised concerns of anecdotal evidence that the practice pathway criteria disproportionately disadvantaged women, although intentional bias was not suspected by the signers of the letter. The petition's signers submitted the following demands to the ABP:

- "Facilitate a timely analysis to determine if gender bias is present or perform this analysis internally and release the findings publicly.

- Revise the practice pathway criteria to be more inclusive of applicants with interrupted practice and varied clinical experience, to include clear-cut parameters rather than considering these applications on a closed-door 'case-by-case basis... at the discretion of the ABP'.

- Clarify the appeals process and improve responsiveness to appeals and inquiries regarding denials.

- Provide a formal response to this petition letter through the PHM ListServ and/or the ABP website within one week of receiving the signed petition." 6

\section{THE ABP RESPONSE TO THE PHM PETITION}

A formal response to the petition was released on the AAP SOHM Listserv on August 29, 2019, to address the concerns raised and is published in this issue of the Journal of Hospital Medicine. ${ }^{4}$ In response to the allegation of gender bias, the ABP maintained that the data did not support this, as the denial rate for females (4.0\%) was not significantly different than 
that for males (3.7\%). The response acknowledged that once clear-cut criteria were decided upon to augment the general practice pathway criteria published at the outset, these criteria should have been disseminated. The ABP maintained, however, that these criteria, once established, were used consistently in adjudicating all applications. To clarify and simplify the eligibility criteria, the percentage of the full-time equivalent and practice interruption criteria were removed, as the work-hours criteria (direct patient care of hospitalized children $\geq 450-500$ hours per year every year for the preceding four years $)^{8}$ were deemed sufficient to ensure adequate clinical participation.

\section{SHM'S POSITION REGARDING THE PHM PETITION AND ABP RESPONSE}

The Society of Hospital Medicine (SHM), through pediatric hospitalists and pediatricians on its Board, committees, and the Executive Council of the Pediatric Special Interest Group, has followed with great interest the public debate surrounding the PHM certification process and the subsequent PHM petition to the ABP. The ABP responded swiftly and with full transparency to the petition, and SHM supports these efforts by the $\mathrm{ABP}$ to provide a timely, honest, data-driven response to the concerns raised by the PHM petition. SHM recognizes that the mission of the ABP is to provide the public with confidence that physicians with ABP board certifications meet appropriate "standards of excellence". While the revisions implemented by the ABP in its response still may not satisfy the concerns of all members of the PHM community, SHM recognizes that the revised requirements remain true to the mission of the ABP.

SHM applauds the authors and signatories of the PHM petition for bravely raising their concerns of gender bias and lack of transparency. The response of the ABP to this petition by further improving transparency serves as an example of continuous improvement in collaborative practice to all medical specialty boards.

While SHM supports the ABP response to the PHM petition, it is clear that excellent physicians caring for hospitalized children will be unable to achieve PHM board certification for a variety of reasons. For these physicians who are not PHM board certified as pediatric hospitalists by the ABP, SHM supports providing these physicians with recognition as hospitalists. These include "niche" hospitalists, such as newborn hospitalists, subacute hospitalists, and subspecialty hospitalists. SHM will also continue to support and recognize community-based hospitalists, family medicine-trained hospitalists, and Med-Peds hospitalists whose practice may not comply with criteria laid out by the ABP. For these physicians, receiving Fellow designation through SHM, a merit-based distinction requiring demonstration of clinical excellence and commitment to hospital medicine, is another route whereby physicians can achieve designation as a hospitalist.

\section{FUTURE DIRECTIONS FOR PEDIATRIC HOSPITALISTS}

SHM supports future efforts by the ABP to be vigilant for bias of any sort in the certification process. Other future considerations for the PHM community include the possibility of a focused practice pathway in hospital medicine (FPHM) for pediatrics as is currently jointly offered by the American Board of Internal Medicine (ABIM) and the American Board of Family Medicine (ABFM). This maintenance of certification program is a variation of internal medicine or family medicine recertification, not a subspecialty, but allows physicians practicing primarily in inpatient settings to focus continuing education efforts on skills and attitudes needed for inpatient practice. ${ }^{9}$ While this possibility was discounted by the ABP in the past based on initially low numbers of physicians choosing this pathway, this pathway has grown from initially attracting 150 internal medicine applicants yearly to 265 in 2015. ${ }^{10}$ The ABMS approved the ABIM/ABFM FPHM as its first approved designation in March 2017 after more than 2,500 physicians earned this designation. ${ }^{11}$ Of the $>2,800$ pediatric residency graduates (not including combined programs) each year, $10 \%$ report planning on becoming pediatric hospitalists, ${ }^{12}$ and currently only 72-74 fellows graduate from PHM fellowships yearly. ${ }^{13}$ FPHM for pediatric hospital medicine would provide focused maintenance of certification and hospitalist designation for those who cannot match to fellowship programs.

\section{Acknowledgments}

The authors would like to acknowledge the input and support from the Executive Council of the Society of Hospital Medicine Pediatric Special Interest Group in writing this statement.

Disclosures: Dr. Chang served as an author of the Pediatric Hospital Medicine Petition to the American Board of Pediatrics for Subspecialty Certification. Drs. Hopkins, Rehm, Gage, and Shen have nothing to disclose.

\section{References}

1. Freed GL, Dunham KM, Research Advisory Committee of the American Board of P. Characteristics of pediatric hospital medicine fellowships and training programs. J Hosp Med. 2009:4(3):157-163. https://doi.org/10.1002/jhm.409.

2. Stucky ER, Maniscalco J, Ottolini MC, et al. The Pediatric Hospital Medicine Core Competencies Supplement: a Framework for Curriculum Development by the Society of Hospital Medicine with acknowledgement to pediatric hospitalists from the American Academy of Pediatrics and the Academic Pediatric Association. J Hosp Med. 2010;5 Suppl 2:i-xv, 1-114. https://doi.org/10.1002/jhm.776.

3. Barrett DJ, McGuinness GA, Cunha CA, et al. Pediatric Hospital Medicine: A Proposed New Subspecialty. Pediatrics. 2017;139(3). https://doi.org/10.1542/ peds.2016-1823

4. Nichols DG WS. The American Board of Pediatrics response to the Pediatric Hospital Medicine petition. J Hosp Med. 2019;14(10):586-588. https://doi. org/10.12788/jhm.3322.

5. Pediatric hospital medicine certification. American Board of Pediatrics. https:// www.abp.org/content/pediatric-hospital-medicine-certification\#training. Accessed 3 September, 2019

6. Skey D. Pediatric Hospitalists, It's time to take a stand on the PHM Boards Application Process! Five Dog Development, LLC. https://www.phmpetition. com/. Accessed 3 September, 2019.

7. Skey D. Petition Update. In: AAP SOHM Listserv: American Academy of Pediatrics; 2019.

8. The American Board of Pediatrics Response to the Pediatric Hospital Medicine Petition. The American Board of Pediatrics. https://www.abp.org/sites/abp/ files/phm-petition-response.pdf. Published 2019. Accessed September 4, 2019.

9. Focused practice in hospital medicine. American Board of Internal Medicine. https:// www.abim.org/maintenance-of-certification/moc-requirements/focused-practice-hospital-medicine.aspx. Published 2019 Accessed September 4, 2019.

10. Butterfield S. Following the focused practice pathway. American College of Physicians. Your career Web site. https://acphospitalist.org/archives/2016/09/focused-practice-hospital-medicine.htm. Published 2016. Accessed September 4, 2019.

11. American Board of Medical Specialties Announces New, Focused Practice Designation [press release]. American Board of Medical Specialties, 14 Mar 2017.

12. Leyenaar JK, Frintner MP. Graduating Pediatric Residents Entering the Hospital Medicine Workforce, 2006-2015. Acad Pediatr. 2018;18(2):200-207. https://doi.org/10.1016/j.acap.2017.05.001.

13. PHM Fellowship Programs. PHMFellows.org. http://phmfellows.org/ phm-programs/. Published 2019. Accessed September 4, 2019 